\title{
Consultório Odontológico: uma AET utilizando-se da EWA
}

\author{
Odontologic clinic: an AET being used of the Ewa
}

BORMIO, Mariana Falcão; Doutoranda em Design; Faculdade de Arquitetura, Arte e Comunicação

Universidade Estadual Paulista - Bauru

marianabormio@uol.com.br

ORENHA, Eliel Soares; Doutor em Odontologia Preventiva e Social; Faculdade de Odontologia de São José dos Campos

Universidade Estadual Paulista - Bauru

eliel@fosjc.unesp.br

SILVA, José Carlos Plácido da; Professor Titular do Departmento de Desenho Industrial;

Universidade Paulista, Bauru

placido@faac.unesp.br

COSTA, Ana Paula Silva da; Doutoranda em Arquitetura e Urbanismo;

Universidade de Campinas - Campinas

anap_scosta@hotmail.com

SANTOS, João Eduardo Guarnetti dos; Professor Livre Docente do Departamento de Engenharia Mecânica; Faculdade de Engenharia Universidade Estadual Paulista, Bauru

guarnetti@feb.unesp.br

\begin{abstract}
Resumo
Este trabalho relata os primeiros passos de um projeto maior, que tem por objetivo desenvolver a avaliação ergonômica de consultórios odontológicos instalados nas Unidades Básicas de Saúde dos municípios paulistas de São José dos Campos e Bauru. Busca-se ao fim do trabalho ter caracterizadoos, possibilitando assim a análise da maneira como ocorre a interface entre os usuários, equipamentos e ambiente. Para tanto serão utilizadas algumas metodologias consagradas no cenário internacional. Relata-se os resultados obtidos com a primeira análise desenvolvida, como teste par calibração das metodologias escolhidas, assim como determinação de procedimentos e tempos gastos, para planejamento do processo.
\end{abstract}

Palavras Chave: Avaliação ergonômica; Conforto ambiental; Odontologia; Ambiente construído.

\begin{abstract}
This work tells the first steps of a larger project, that has for objective to develop the ergonomic evaluation of clinics odontologics installed in the Basic Units of Health of the municipal districts from São Paulo of São José dos Campos and Bauru. It is looked for to the end of the work to have characterized them, making possible like this the analysis in the way as it happens the interface among the users, equipments and atmosphere. For so much some will be used methodologies consecrated in the international scenery. It is told the results obtained with the first developed analysis, as test equal calibration of the chosen methodologies, as well as determination of procedures and worn-out times, for planning of the process.
\end{abstract}

Keywords: Ergonomic analysis; Environment confort; Odontologic; Environment built.

Projética Revista Científica de Design I Universidade Estadual de Londrina I V.2 I N.1 I Junho 2011 


\section{Introdução}

Considerando o trabalho em sua forma mais ampla, como qualquer atividade realizada pelo ser humano, pode-se dizer que intrínseco ao seu desenvolvimento, tem-se custos e benefícios. Enquanto custos citam-se os psicológicos e físicos, dentre os quais se tem como possíveis fontes geradoras, as cobranças por altas produtividades, jornadas excessivas de trabalho, ambientes e ferramentas mal dimensionadas, ou seja, quando não está devidamente direcionado às reais necessidades dos usuários e suas particularidades.

Quando se fala em ambiente construído, torna-se importante destacar que é a partir da maneira como ele encontra-se configurado, composição arquitetônica, formas, cores, fatores físicos ambientais (ruídos, iluminação, temperatura, entre tantos outros), mobiliário, layout; que conjugados geram condições que permitam que as atividades humanas ocorram de maneira a proporcionar saúde, segurança e bem-estar ao homem.

Neste trabalho os olhares se direcionam aos profissionais de odontologia e seu posto de trabalho. Atenção esta justificada pelos grandes índices de ocorrência de doenças identificados nesses profissionais, principalmente as do sistema osteomusculares, pois, para desenvolverem suas atividades assumem posturas que restringem seus movimentas, além de exigirem constantes torções e flexões do corpo, além de esforços e repetitividade.

Para o desenvolvimento desse estudo, estabeleceu-se uma parceria entre as Faculdades de Arquitetura, Artes e Comunicação - FAAC, campus Bauru; e de Odontologia, campus São José dos Campos; da Universidade Estadual Paulista; de maneira a tirar partido da interdisciplinaridade, enquanto troca de conhecimentos, aprofundando assim os estudos desenvolvidos nos últimos anos, e consequentemente, alcançando resultados que gerem propostas cujas soluções atendam da melhor maneira as necessidades dos usuários do posto de trabalho odontológico.

A primeira parte do trabalho consistiu na definição das metodologias a serem utilizadas, onde optou pela adoção do Questionário Nórdico de Sistemas Osteomusculares, o protocolo Ergonomic Workplace Analysis - EWA (Análise Ergonômica do Posto de trabalho), e pelo Esquema Gráfico do ISO e FDI. O segundo passo foi à aplicação de um teste piloto, que buscou identificar se as metodologias escolhidas são satisfatórias enquanto contemplarem os itens que devem ser avaliados no posto de trabalho em questão, assim como, estipular um tempo médio gasto nesse procedimento e os materiais necessários, para desenvolver a coleta de dados efetiva.

Finalizando serão tecidas considerações a partir dos resultados obtidos.

\section{O Posto de Trabalho Odontológico}

Entende-se o posto de trabalho, segundo lida (2006, p. 189), como sendo a configuração física do sistema homem-máquina-ambiente, enquanto a "unidade produtiva envolvendo um homem e o equipamento que ele utiliza para realizar o trabalho, bem como o ambiente que o circunda".

No caso do dentista, seu posto de trabalho é definido meio a uma vasta gama de equipamentos, mobiliários e o ambiente. Pode-se dizer que diante de tal complexidade, a conjugação adequada torna-se um desafio, pois, entre outros aspectos, exige concentração e precisão de movimentos, regidos pela não existência de um posicionamento postural definido, pois, ocorre uma busca constante por um bom campo visual de trabalho diante do 
Consultório Odontológico: uma AET utilizando-se da EWA

paciente, somado à necessidade de alcance dos instrumentos a serem utilizados. Esse contexto estabelece repetitividade de movimentos, além de rotação do tronco, flexão da cabeça forçando a musculatura cervical, escapular e tóraco-lombar; manutenção dos membros superiores suspensos; entre outros constrangimentos corporais. Como resposta, Rasia (2004), cita a comumente presença de dores e fadiga nas regiões cervical, escapular, lombar e em outras estruturas envolvidas na manutenção dos movimentos citados, podendo gerar lesões agudas ou crônicas nas mesmas. $\mathrm{O}$ quadro 1 relaciona alguns movimentos realizados pelos dentistas, exemplificando enquanto atos.

\begin{tabular}{|l|l|}
\hline Movimento & Exemplo \\
\hline Somente dos dedos & Pegar um rolete de algodão \\
\hline De dedos e punho & Manipulação de instrumento manual \\
\hline Dedos, punho e cotovelo & Alcançar a caneta de alta-rotação \\
\hline Todo o braço e ombro & $\begin{array}{l}\text { Alcançando materiais além da área de trabalho, sem, contudo, } \\
\text { realizar torção da coluna }\end{array}$ \\
\hline Torção completa do tronco & Quando o profissional vira-se para alcançar um equipamento \\
\hline
\end{tabular}

Quadro 1 - Classificação dos Movimentos do Cirurgião-dentista.

Fonte: Rasia (2004).

Rasia (2004) em seu trabalho define alguns fatores causais para as doenças Distúrbio Osteomuscular Relacionado ao Trabalho - DORT, destacando entre eles:

- Fatores de Natureza Organizacional: concentração de movimentos numa mesma pessoa, horas extraordinárias, dobras de turno, ritmo acelerado de trabalho, ausência das pausas necessárias, pressão da chefia, entre outros.

-Fatores de Natureza Biomecânica: força excessiva, alta repetitividade de um mesmo padrão de movimento, posturas incorretas dos membros superiores, compressão das estruturas dos membros superiores, postura estática, entre outros.

- Fatores de Natureza Psicossocial: pressão excessiva para os resultados, ambiente de trabalho excessivamente tenso, problemas de relacionamento interpessoal, rigidez excessiva no sistema de trabalho, entre outros.

- Fatores de Condições de Trabalho: temperatura, vibração, mobiliário, ruído, iluminação, espaço, ferramentas entre outros.

No documento Serviços Odontológicos: Prevenção e Controle de Riscos; desenvolvido pela ANVISA (BRASIL, 2006), são considerados como riscos ocupacionais a possibilidade e a probabilidade de que perda ou dano ocorra, enquanto ocorrência de um evento adverso. Segundo o documento, os riscos mais freqüentes a que estão sujeitos os profissionais que atuam em assistência odontológica são:

- Os físicos: ruído, vibração, radiação ionizante e não ionizante, além de temperaturas extremas, iluminação deficiente ou excessiva, umidade e outros. São causadores desses riscos: caneta de alta rotação, compressor de ar, equipamento de RX, equipamento de laser, fotopolimerizador, autoclave, condicionador de ar, etc;

- Os químicos: poeiras, névoas, vapores, gases, mercúrio, produtos químicos em geral e outros. Os principais causadores desses riscos são: amalgamadores, 
Mariana F. Bormio; Eliel S. Orenha; José C. P. da Silva; Ana Paula S. da Costa; João E. G.dos Santos

desinfetantes químicos (álcool, glutaraldeído, hipoclorito de sódio, ácido peracético, clorexidina, entre outros) e os gases medicinais (óxido nitroso e outros);

- Os ergonômicos: postura incorreta, ausência de um profissional auxiliar e/ou técnico, falta de capacitação do pessoal auxiliar, atenção e responsabilidade constantes, ausência de planejamento, ritmo excessivo, atos repetitivos, entre outros;

- Os mecânicos ou de acidente: entre os mais frequentes, podemos citar: espaço físico subdimensionado, arranjo físico inadequado, instrumental com defeito ou impróprio para o procedimento, perigo de incêndio ou explosão; edificação com defeitos; improvisações na instalação da rede hidráulica e elétrica; ausência de EPI e outros;

-Por ausência de conforto no ambiente de trabalho: sanitário em número insuficiente e sem separação por gênero e falta de produtos de higiene pessoal, como sabonete líquido e toalha descartável nos lavatórios, ausência de água potável para consumo, não fornecimento de uniformes, ausência de ambientes arejados para lazer e confortáveis para descanso, ausência de vestiários com armários para a guarda de pertences, falta de local apropriado para lanches ou refeições, falta de proteção contra chuva, entre outros;

- Os biológicos: a probabilidade da ocorrência de um evento adverso em virtude da presença de um agente biológico. Sabe-se que as exposições ocupacionais a materiais biológicos potencialmente contaminados constituem um sério risco aos profissionais da área da saúde nos seus locais de trabalho. Estudos desenvolvidos nesta área mostram que os acidentes envolvendo sangue e outros fluidos orgânicos correspondem às exposições mais freqüentemente relatadas.

Para atuar sobre essas configurações deve-se, a princípio, buscar entendê-las a fim de definir parâmetros que resultem em propostas que viabilizem o bem-estar dos sujeitos, a eficiência e a eficácia da atividade. A melhor maneira é a realização de uma Análise Ergonômica do Trabalho-AET; ou seja, caracterizar as situações reais de trabalho, sendo indispensável saber o que os trabalhadores realmente fazem como fazem e porque fazem. Para tanto, utilizamse de medições técnicas, levantamentos dos aspectos arquiteturais e mobiliários, medições do dimensionamento e dos fatores físico-ambientais como temperatura, luminosidade, ruído; questionários e formulários; check-lists, entrevistas; observação de comportamento e usos; documentação através de imagens fotográficas e vídeos; documentação gráfica - projeto arquitetônico, croquis e simulações; realizadas de maneira técnica e subjetiva, pelo avaliador e pelo usuário.

A AET pode ser desenvolvida por meio de APO - Avaliação Pós Ocupação, que segundo Ornstein e Romero (1992), diz respeito a uma série de métodos e técnicas que diagnosticam fatores positivos e negativos do ambiente no decorrer do uso, a partir da análise de fatores socioeconômicos, de infra-estrutura e superestruturas urbanas dos sistemas construtivos, conforto ambiental, conservação de energia, fatores estéticos, funcionas e comportamentais. Uma APO compreende várias etapas: coleta ou levantamento de dados, diagnóstico, recomendações para o ambiente - estudo de caso e insumos para os novos projetos (ORNSTEIN, 1991 apud ORNSTEIN; ROMERO, 1992).

De acordo com a APO, o ambiente construído pode ser trabalhado a partir de algumas variáveis que irão gerar tipos diferenciados de avaliações, conforme relacionado no quadro 2. 
Consultório Odontológico: uma AET utilizando-se da EWA

\begin{tabular}{|c|c|c|}
\hline Tipo de avaliação & Objetivo & Possiveis variáveis a serem trabalhadas \\
\hline \multirow[t]{2}{*}{$\begin{array}{l}\text { Técnico-construtiva } \\
\text { conforto } \\
\text { ambiental }\end{array}$} & \multirow[t]{2}{*}{$\begin{array}{l}\text { Reconhecimento } \\
\text { especializado do } \\
\text { ambiente/estudo de caso }\end{array}$} & $\begin{array}{l}\text { Materiais e técnicas construtivas que abrange: solos e } \\
\text { fundações, alvenarias, revestimentos, pinturas e } \\
\text { paisagismo, dentre outros; }\end{array}$ \\
\hline & & $\begin{array}{l}\text { Conforto ambiental que abrange: conforto térmico, } \\
\text { iluminação natural e artificial, conforto acústico, } \\
\text { dentre outros; }\end{array}$ \\
\hline \multirow{5}{*}{$\begin{array}{l}\text { Técnico } \\
\text { funcional }\end{array}$} & \multirow{5}{*}{$\begin{array}{l}\text { Avaliação feita pelos } \\
\text { pesquisadores no que diz } \\
\text { respeito ao desempenho } \\
\text { funcional dos espaços } \\
\text { resultantes }\end{array}$} & Planejamento/programa do projeto \\
\hline & & Áreas e dimensionamentos mínimos \\
\hline & & $\begin{array}{l}\text { Adequação do mobiliário fixo, móveis e equipamentos } \\
\text { especiais }\end{array}$ \\
\hline & & Flexibilização dos espaços \\
\hline & & $\begin{array}{l}\text { Adequação externa e interna a deficientes fisicos e } \\
\text { visuais, dentre outros aspectos }\end{array}$ \\
\hline \multirow[t]{3}{*}{ Técnico-econômica } & \multirow{3}{*}{$\begin{array}{l}\text { Diz respeito aos indices } \\
\text { econômicos extraídos da } \\
\text { produção e uso do } \\
\text { ambiente construído }\end{array}$} & Relação custo/beneficio \\
\hline & & Variação por metro quadrado de área construida \\
\hline & & Variação dos custos de manutenção do edificio em uso \\
\hline $\begin{array}{l}\text { Técnico } \\
\text {-estética }\end{array}$ & $\begin{array}{l}\text { Diz respeito ao estilo e da } \\
\text { percepção ambiental, } \\
\text { levando-se } \\
\text { consideração tanto a } \\
\text { opinião do avaliador- } \\
\text { arquiteto quanto do } \\
\text { usuário }\end{array}$ & $\begin{array}{l}\text { Cores/pigmentação; texturas; volumetria; efeitos } \\
\text { luminicos, dentre outros. }\end{array}$ \\
\hline Comportamental & $\begin{array}{l}\text { Refere-se ao ponto de vista } \\
\text { do usuário, podendo-se } \\
\text { utilizar várias técnicas para } \\
\text { tais fins. Como variáveis } \\
\text { tem-se adequação ao uso e } \\
\text { escala humana, } \\
\text { privacidade, território, } \\
\text { proximidade, dentre outros }\end{array}$ & \\
\hline Estrutura organizacional & $\begin{array}{l}\text { Identifica problemas de } \\
\text { organização funcional ou } \\
\text { gerencial }\end{array}$ & \\
\hline
\end{tabular}

Quadro 2 - APO: tipo de avaliação, objetivo e possíveis variáveis.

Fonte: Ornstein e Romero (1992).

Atualmente a ergonomia em sua constante busca pelo entendimento da interface homem / trabalho / ambiente, assume um papel indiscutivel de importância no contexto do ambiente de trabalho mundial, facilmente comprovado pelo grande número de trabalho em franco desenvolvimento. Uma das justificativas mais consistentes para esse fato é o uso da interdisciplinaridade com outras áreas, diante do objetivo principal de entender a maneira como ocorre a relação em questão.

Rasia (2004) cita que as primeiras contribuições da Ergonomia no campo da Odontologia destinaram-se a melhorar as condições de trabalho dos cirurgiões dentistas, criando e aperfeiçoando as ferramentas, instrumentos e mobiliário utilizado por esses profissionais. $E$ complementa destacando que o objetivo é a diminuição do estresse físico e mental, prevenindo assim as doenças relacionadas à prática odontológica, e conseqüentemente buscando uma produtividade mais expressiva.

\section{Metodologias}


Mariana F. Bormio; Eliel S. Orenha; José C. P. da Silva; Ana Paula S. da Costa; João E. G.dos Santos

Muitas são as metodologias existentes para o desenvolvimento de AET, para o posto em questão adotou-se o Questionário Nórdico de Sistemas Osteomusculares, o protocolo Ergonomic Workplace Analysis - EWA (Análise Ergonômica do Posto de trabalho), e pelo Esquema Gráfico do ISO e FDI. A seguir serão apresentadas informações a respeito de cada metodologia.

\section{Questionário Nórdico de Sistemas Osteomusculares}

O Nordic Musculoskeletal Questionnaire - NMQ, Figura 01, foi desenvolvido com a proposta de padronizar a mensuração de relato de sintomas osteomusculares e, assim, facilitar a comparação dos resultados entre os estudos. Os autores desse questionário não o indicam como base para diagnóstico clínico, mas para a identificação de distúrbios osteomusculares e, como tal, pode constituir importante instrumento de diagnóstico do ambiente ou do posto de trabalho (PINHEIRO; TRÓCCOLI; CARVALHO, 2002). Sua eficácia pode ser constatada pelo fato desse questionário já ter sido traduzido para diversos idiomas na última década.

A metodologia é estruturada em um questionário onde as questões estruturam-se a partir de um esquema estipulado do corpo humano, dividido em nove partes, cujas respostas são escolhidas entre as alternativas "sim" ou "não", quanto à ocorrência de sintomas nas diversas regiões anatômicas nas quais são mais comuns.

O respondente deve relatar a ocorrência dos sintomas considerando os doze meses e os sete dias precedentes à entrevista, bem como relatar a ocorrência de afastamento das atividades rotineiras no último ano.

\begin{tabular}{|c|c|c|c|c|c|c|}
\hline & & & \multicolumn{4}{|c|}{$\begin{array}{l}\text { Questionário Nórdico } \\
\text { dos sintomas } \\
\text { músculo-esquelético }\end{array}$} \\
\hline \multirow{2}{*}{\multicolumn{3}{|c|}{ 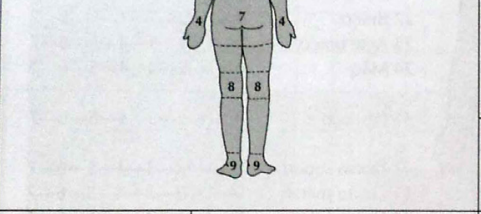 }} & \multicolumn{4}{|c|}{$\begin{array}{l}\text { Marque um }(x) \text { na resposta apropriada. Marque apenas um }(x) \\
\text { para cada questáo. } \\
\text { Não, indica conforto, saúde - Sim, indica incômodos, descon- } \\
\text { fortos, dores nessa parte do corpo. }\end{array}$} \\
\hline & & & \multicolumn{4}{|c|}{$\begin{array}{l}\text { ATENÇĀO: O desenho ao lado representa apenas uma posiçăo } \\
\text { aproximada das partes do corpo. Assinale a parte que mais se } \\
\text { proxima do seu problema }\end{array}$} \\
\hline $\begin{array}{l}\text { Partes do corpo } \\
\text { com problemas }\end{array}$ & \multicolumn{2}{|c|}{$\begin{array}{c}\text { Você teve algum problema } \\
\text { nos últimos } 7 \text { dias? }\end{array}$} & \multicolumn{2}{|c|}{$\begin{array}{c}\text { Você teve algum problema } \\
\text { nos últimos } 12 \text { meses? }\end{array}$} & \multicolumn{2}{|c|}{$\begin{array}{l}\text { Você teve que deixar de traba } \\
\text { Ihar algum dia nos últimos } 12 \\
\text { meses devido ao problema? }\end{array}$} \\
\hline 1 - Pescoço & $1 \square$ Não & $2 \square \mathrm{Sim}$ & $1 \square$ Não & $2 \square \mathrm{Sim}$ & $1 \square$ Năo & $2 \square \mathrm{Sim}$ \\
\hline 2-Ombros & $\begin{array}{l}1 \square \text { Não } \\
2 \square \operatorname{Sim}-\text { om } \\
3 \square \operatorname{Sim}-\text { om } \\
4 \square \operatorname{Sim}-\text { os } C\end{array}$ & $\begin{array}{l}\text { direito } \\
\text { esquerdo } \\
\text { ombros }\end{array}$ & $\begin{array}{l}1 \square \text { Não } \\
2 \square \operatorname{Sim}-\text { om } \\
3 \square \operatorname{Sim}-\text { om } \\
4 \square \operatorname{Sim} \text { - os C }\end{array}$ & $\begin{array}{l}\text { direito } \\
\text { esquerdo } \\
\text { ombros }\end{array}$ & $1 \square$ Não & $2 \square \mathrm{Sim}$ \\
\hline 3 - Cotovelos & $\begin{array}{l}1 \square \mathrm{Não} \\
2 \square \mathrm{Sim}-\cot \\
3 \square \mathrm{Sim}-\cot \\
4 \square \mathrm{Sim}-\mathrm{os} c\end{array}$ & $\begin{array}{l}\text { direito } \\
\text { esquerdo } \\
\text { cotovelos }\end{array}$ & $\begin{array}{l}1 \square \text { Não } \\
2 \square \mathrm{Sim}-\operatorname{cotc} \\
3 \square \mathrm{Sim}-\cot \\
4 \square \mathrm{Sim}-\mathrm{os} C\end{array}$ & $\begin{array}{l}\text { direito } \\
\text { cosquerdo } \\
\text { cotovelos }\end{array}$ & $1 \square$ Não & $2 \square \operatorname{Sim}$ \\
\hline 4 - Punhos e mãos & $\begin{array}{l}1 \square \mathrm{Não} \\
2 \square \mathrm{Sim} \text { - pur } \\
3 \square \mathrm{Sim} \text { - pur } \\
4 \square \mathrm{Sim} \text { - os }\end{array}$ & $\begin{array}{l}\text { não direita } \\
\text { não esquerda } \\
\text { punho/mão }\end{array}$ & $\begin{array}{l}1 \square \text { Não } \\
2 \square \mathrm{Sim} \text { - pun } \\
3 \square \mathrm{Sim} \text { - pun } \\
4 \square \mathrm{Sim} \text { - os }\end{array}$ & $\begin{array}{l}\text { mão direita } \\
\text { mão esquerda } \\
\text { punho/mão }\end{array}$ & & \\
\hline 5 - Coluna dorsal & $1 \square$ Não & $2 \square \mathrm{Sim}$ & $1 \square$ Năo & $2 \square \mathrm{Sim}$ & $1 \square$ Não & $2 \square \mathrm{Sim}$ \\
\hline 6 - Coluna lombar & $1 \square$ Não & $2 \square \mathrm{Sim}$ & $1 \square$ Não & $2 \square \operatorname{Sim}$ & $1 \square$ Não & $2 \square \mathrm{Sim}$ \\
\hline 7- Quadril ou coxas & $1 \square$ Não & $2 \square \mathrm{Sim}$ & $1 \square$ Năo & $2 \square \mathrm{Sim}$ & $1 \square$ Não & $2 \square \mathrm{Sim}$ \\
\hline 8 - Joelhos & $1 \square$ Não & $2 \square \mathrm{Sim}$ & $1 \square$ Não & $2 \square \mathrm{Sim}$ & $1 \square$ Não & $2 \square \mathrm{Sim}$ \\
\hline 9 - Tornozelo ou pés & $1 \square$ Não & $2 \square \mathrm{Sim}$ & $1 \square$ Năo & $2 \square \operatorname{Sim}$ & $1 \square$ Năo & $2 \square \mathrm{Sim}$ \\
\hline
\end{tabular}

Figura 1 - Questionário Nórdico de Sistemas Osteomusculares.

Fonte: lida (2006). 
Consultório Odontológico: uma AET utilizando-se da EWA

lida (2006) lembra que o questionário deve ser distribuído juntamente com uma carta explicativa dos objetivos do levantamento e solicitando colaboração; seguido de um bloco de caracterização do sujeito, pedindo-Ihe para indicar o gênero, idade, lateralidade (se é destro, canhoto ou ambidestro). Finalmente, indica-se onde devem ser entregue os questionários preenchidos, e se faz um agradecimento pela colaboração.

\section{EWA - Ergonomic Workplace Analysis}

A metodologia EWA - "Ergonomic Workplace Analysis" - Análise Ergonômica do Local de trabalho, foi desenvolvida por Ahonem et al. (1989); e se destaca pela importância histórica, no contexto de análise ergonômica do local de trabalho, caracterizada por abordagens subjetivas e objetivas.

Esta metodologia consiste em uma APO - Avaliação Pós-ocupação, desenvolvida por meio da aplicação de um protocolo que avalia o local de trabalho, por meio de uma abordagem ampla, que possibilita diferentes enfoques, seja de forma geral, enfocando o ambiente como um todo, ou mesmo pontual, como por exemplo o mobiliário, de maneira a não somente caracterizar fisicamente o local de trabalho, mas também a percepção do usuário e do avaliador em relação ao processo de trabalho.

O EWA, Figura 2, foi criado em 1984 pelo FIOH - Finnish Institute of Occupational Health (Instituto Finlandês de Saúde Ocupacional), em Helsink, tendo como autores Mauno Ahonen, Martti Launis e Tuulikki Kuorinka, e em 1989 teve sua publicação adaptada para uma versão em inglês.

Sua criação atribuiu-se a busca pela superação de um contexto crescente de incidência de doenças ocupacionais, por parte do governo finlandês, que colocou em vigor a lei de higiene ocupacional, que exigia unidades de cuidado higiênico dos empreendimentos; inspeção de funcionamento, condicionado ao empreendimento; e avaliação dos seus possíveis efeitos na saúde dos trabalhadores.

Considera-se, portanto, que a criação deste método foi pensada buscando uma ferramenta de análise ergonômica, capaz de captar sob diferentes aspectos do local de trabalho, material informativo que transmitisse, ao ser utilizado, informações aos profissionais (projetistas - arquitetos e designers, e especialistas da saúde) de maneira a facilitar ações como: a contratação de pessoal; realização de correções - checando a qualidade das melhorias feitas, tanto em um posto de trabalho, como nas tarefas, seja de um único posto de trabalho ou fazendo comparação de diferentes postos com o mesmo tipo de atividade; e/ou desenvolvimento de novos projetos com configurações seguras, saudáveis e produtivas para os trabalhadores.

Segundo Bormio (2007) a aplicação do EWA é utilizada para a realização de análise ergonômica detalhada do local de trabalho, por meio de itens que enfocam aspectos da fisiologia do trabalho, biomecânica ocupacional, psicológicos, higiene ocupacional, em um modelo participativo com a organização do trabalho. 
Mariana F. Bormio; Eliel S. Orenha; José C. P. da Silva; Ana Paula S. da Costa; João E. G.dos Santos

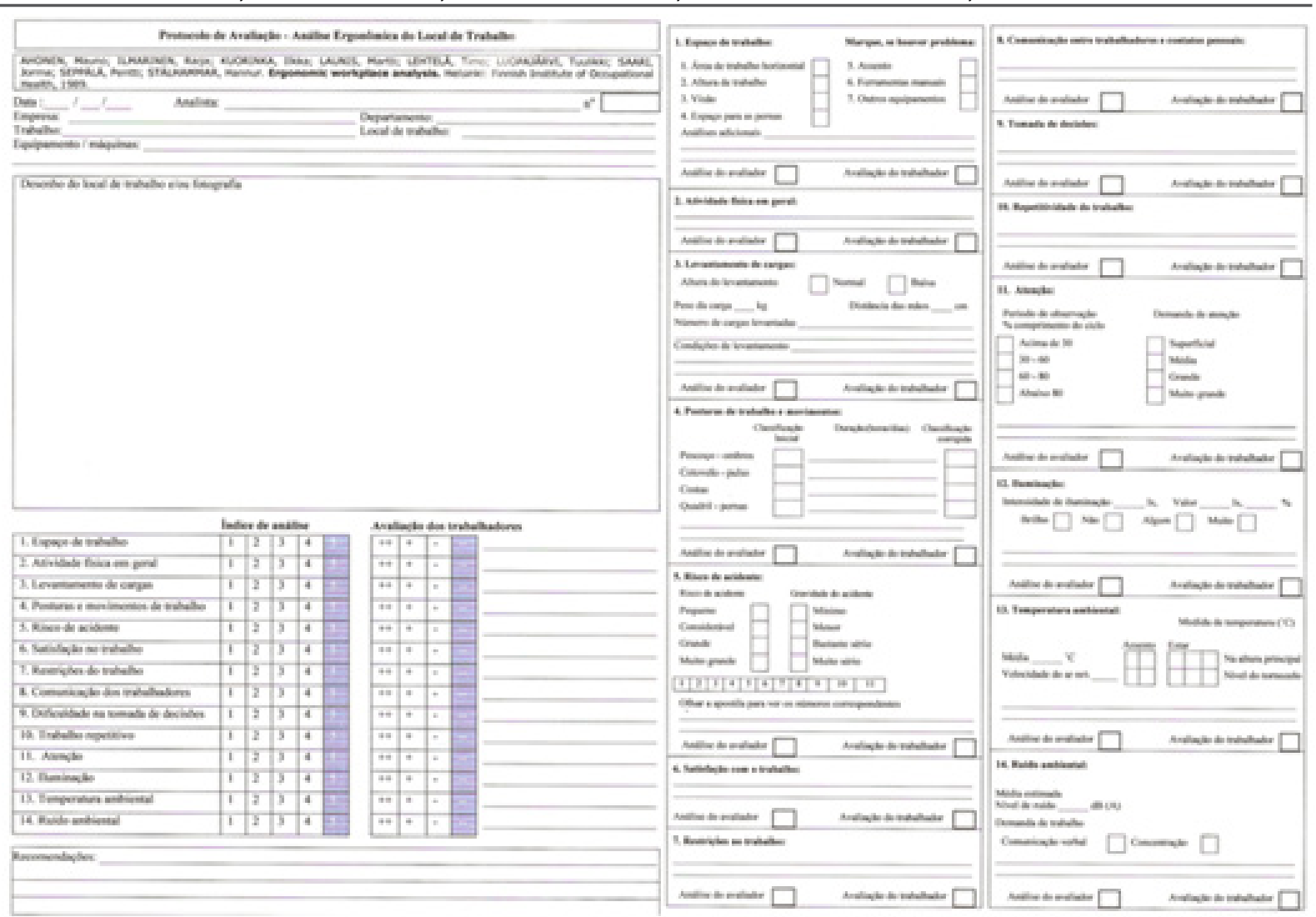

Figura 2 - Protocolo EWA.

Fonte: Bormio, 2007.

O primeiro passo, para aplicação deste protocolo, é a definição e delimitação da tarefa a ser analisada, assim como o local do trabalho, pois diante desses dados a análise é desenvolvida observando inicialmente quatorze questões preestabelecida.

Observa-se que este método possui um caráter flexível, que torna possível, caso se faça necessário, a inclusão e/ou exclusão de elementos na relação dos itens avaliados, pois estes devem corresponder aos fatores relevantes e importantes ao local em questão.

Essas questões são formuladas sob dois critérios:

- Cada item deve ser avaliado de acordo com fatores cuja saúde, segurança e produtividade do posto de trabalho possam ser projetadas e realizadas;

- Os itens devem ser quantificáveis.

Esses itens apresentam-se relacionadas no quadro 3. 
Consultório Odontológico: uma AET utilizando-se da EWA

\begin{tabular}{|c|c|c|}
\hline Variáveis & Fator de avaliação & Indicadores \\
\hline \multirow{10}{*}{ Biomecânicas } & Atividade fisica em geral & - \\
\hline & \multirow[t]{4}{*}{ Levantamento de cargas } & Altura do levantamento \\
\hline & & Distância das măos \\
\hline & & $\begin{array}{l}\text { Nủmero de cargas } \\
\text { levantadas }\end{array}$ \\
\hline & & Condiçōes de levantamento \\
\hline & \multirow{4}{*}{$\begin{array}{l}\text { Posturas de trabalho } \\
\text { e movimentos }\end{array}$} & Pescoco - ombros \\
\hline & & Cotovelo - pulso \\
\hline & & Costas \\
\hline & & Quadril - pernas \\
\hline & Repetitividade do trabalho & - \\
\hline \multirow[t]{2}{*}{ Segurança } & \multirow[t]{2}{*}{ Risco de acidentes } & Intensidade \\
\hline & & Gravidade \\
\hline \multirow[t]{2}{*}{ Psicológicas } & Satisfaçăo com o trabalho & - \\
\hline & Atençăo & - \\
\hline \multirow[t]{3}{*}{ Organizacionais } & Restriç̄es no trabalho & $=$ \\
\hline & $\begin{array}{l}\text { Comunicação entre } \\
\text { trabalhadores e contatos pessoais }\end{array}$ & - \\
\hline & Tomada de decisões & - \\
\hline $\begin{array}{l}\text { Mobiliário / } \\
\text { Espaço de } \\
\text { trabalho }\end{array}$ & Caracteristicas fisicas & $\begin{array}{l}\text { Area de trabalho horizontal } \\
\text { Altura de trabalho } \\
\text { Visão } \\
\text { Espaço para as pernas } \\
\text { Assento } \\
\text { Ferramentas manuais } \\
\text { Outros equipamentos }\end{array}$ \\
\hline \multirow{3}{*}{$\begin{array}{l}\text { Fisico } \\
\text { ambientais }\end{array}$} & Iluminaçăo & - \\
\hline & Temperatura & $=$ \\
\hline & Ruido ambiental & - \\
\hline
\end{tabular}

Quadro 3 - Protocolo de análise do posto de trabalho: variáveis ergonômicas, fatores de avaliação e indicadores.

Fonte: Bormio, 2007.

O preenchimento do protocolo ocorre em três etapas, que serão descritas a seguir:

-Avaliação do usuário: desenvolve-se por meio de entrevista. As perguntas enfocavam as percepções que o usuário tem em relação ao local de trabalho, devendo essas, serem respondidas mediante uma análise subjetiva, expressas por uma classificação variável de bom ++; regular +; ruim -; a muito ruim --• - Medições técnicas e registros fotográficos: as medições referentes aos fatores físico-ambientais deverão ser feitas pelo avaliador, utilizando-se de aparelhos adequados, que devem estar devidamente calibrados e certificados por órgão responsável. Os valores obtidos deverão ser devidamente anotados no campo pré-estabelecido no protocolo. Durante esta etapa registra-se por meio de fotografias ou desenhos o usuário utilizando o local, no contexto geral e pontual. -Análises do Avaliador: essas análises deverão ser desenvolvidas de maneira objetiva e consistem nas percepções que o avaliador possui em relação aos usuários desenvolvendo suas atividades, confrontando os valores resultantes das medições técnicas com os valores indicados pelas normas brasileiras, objetivando assim, determinar o desvio entre as condições de trabalho constatadas no ambiente em relação às recomendações da literatura. Para tanto, obedece-se a uma escala onde os índices de classificação variam de 1 à 5 , sendo 1 -ideal, 2 - bom, 3 -regular, 4 -ruim, e 5 - péssimo. 
Destaca-se que as escalas dos itens não são comparativas, por exemplo, o valor 5 para o item "contatos pessoais" não deve ter o mesmo peso em relação ao valor 5 para o item "ruído". Entretanto, no perfil final, o valor 5 deve chamar atenção especial para o ambiente de trabalho.

\section{Esquema Gráfico do ISO e FDI}

Com o objetivo de orientar a atividade odontológica a Internacional Organization for Standardization - ISO, e a Federation Dentaire Internacionale - FDI, descreveram o sistema de trabalho para esse profissional, por meio de um esquema que se baseia em um relógio imaginário colocado sobre o posto de trabalho odontológico, de maneira a possibilitar a indicação da posição a ser adotada pelo dentista e seu auxiliar durante o atendimento do paciente (CUSTÓDIO, 2006).

Essa metodologia que busca uma análise ergonômica, divide o local de trabalho em áreas, onde as demarcações remetem à um mostrador de relógio, cujo centro corresponde ao eixo dos ponteiros e deve posicionar-se na boca do paciente, deitado na horizontal. A posição de 12 horas é sempre indicada pela cabeça do paciente e a de 6 horas para os pés; dividindo assim a sala em duas áreas: à direita devendo ser ocupada pela a cadeira do dentista, e à esquerda pela cadeira do auxiliar.

A partir do centro traçam-se três círculos concêntricos com raios de respectivamente 0,$5 ; 1,0$; e 1,5 metros, que estabelecem zonas de alcance. A área limitada pelo círculo de raio $0,5 \mathrm{~m}$ denominada de zona de transferência, que abrange tudo que se transfere à boca do paciente; a área de 1,0m de raio delimita a área útil de trabalho que pode ser alcançado com o braço esticado, devem ser posicionadas as mesas auxiliares e armários fixos, prevendo as gavetas aberta; e a área do raio de 1,5m de largura seria o limite do consultório como um todo. A figura 3 exemplifica a aplicação desta metodologia.

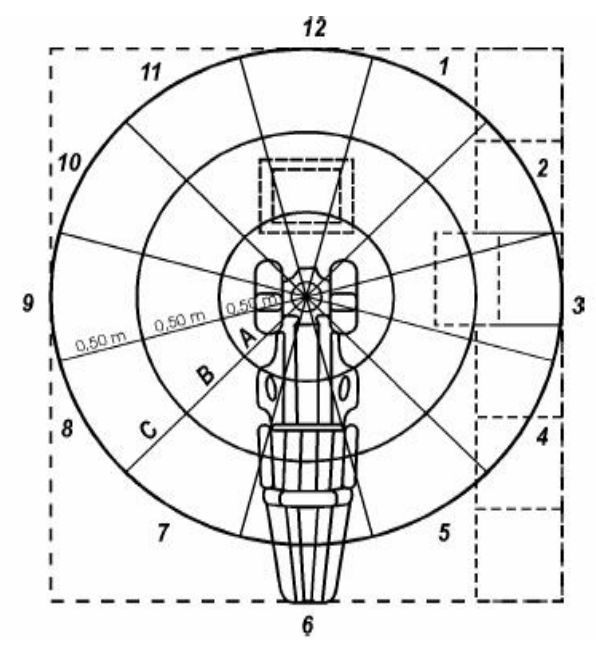

Figura 3 - esquema gráfico ISO/FDI.

Fonte: Porto (1994 apud CUSTÓDIO, 2006).

Todos os aparelhos (equipos, periféricos, bandeja auxiliar com instrumentais e materiais necessários, armários ou gavetas de armários, suctor, terminal de computador) e o campo operatório devem estar em um plano horizontal imaginário que passa a altura do cotovelo do

Projética Revista Científica de Design I Universidade Estadual de Londrina I V.2 I N.1 I Junho 2011 
Consultório Odontológico: uma AET utilizando-se da EWA

dentista quando ergonomicamente sentado. A tolerância de variação de altura para este plano é de até $15 \mathrm{~cm}$ acima do mesmo.

Diante das recomendações estipuladas pela ISO/FDI, Neto (1999, apud SANTOS et al., 2007) considera que em consultórios odontológicos é necessário pensar o layout a partir dessas padronizações. Na figura 4, o autor esquematiza as possíveis posições a serem adotadas pelo dentista com base em um relógio imaginário.

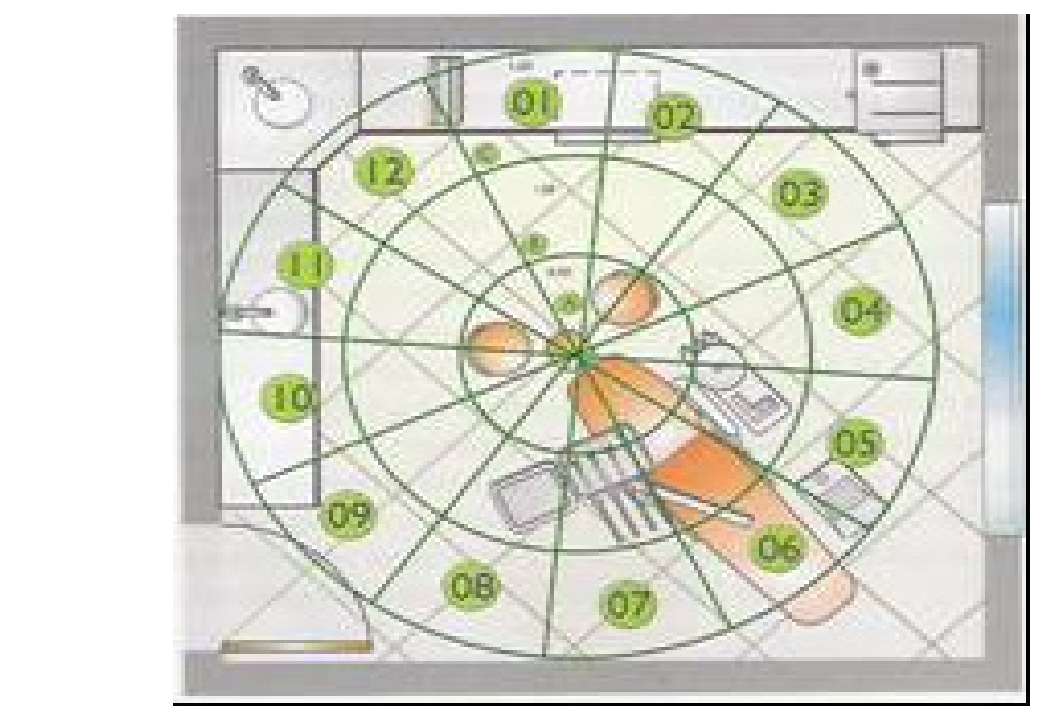

Figura 4 - Diferentes localizações do dentista com base em um relógio imaginário.

Fonte: Custódio, 2006.

Um ambiente de trabalho do dentista é sua sala clínica, dessa maneira, o seu posto de trabalho deve refletir como elemento considerável na acomodação e satisfação dos pacientes e dos que nele trabalham.

\section{Estudo de Caso - Consultório Odontológico “Lar Escola Rafael Maurício”}

É importante relembrar, conforme citado anteriormente, que esse trabalho é parte integrante de um projeto maior, constituindo em um pré-teste para que s possa fazer as devidas adequações nas metodologias e processo de aplicação.

Para seu desenvolvimento, o local escolhido foi à escola municipal "Lar Escola Rafael Maurício", localizado na cidade de Bauru - SP, que possui um consultório odontológico, figuras 5 - 7, com a presença diária do profissional responsável, que é do gênero masculino, com idade de 30 anos.

O primeiro passo consistiu no pedido de autorização da instituição enquanto permissão para o desenvolvimento da pesquisa. Após o aceite da mesma, foi definido um dia para a visita técnica, onde foram feitas as medições de ruído, iluminação e temperatura; definição do layout do consultório, registros fotográficos e preenchimento dos protocolos avaliativos pelo dentista e pelos avaliadores. 0 processo teve um tempo de duração de 40 minutos para sua aplicação. Lembra-se que a tabulação e análise dos resultados foram feitas fora do ambiente de estudo. 


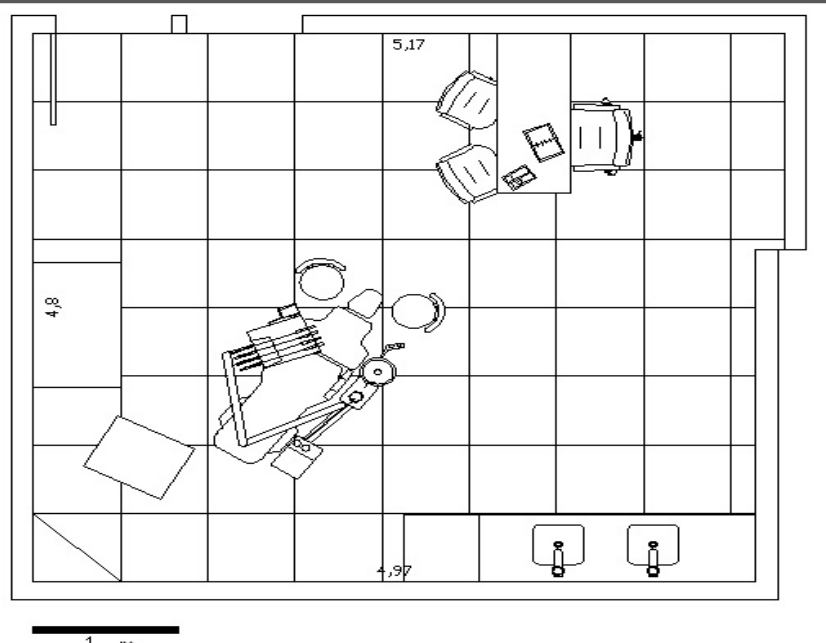

Figura 5 - Planta / layout do consultório do "Lar escola Rafael Maurício"

Fonte: Arquivo dos Autores

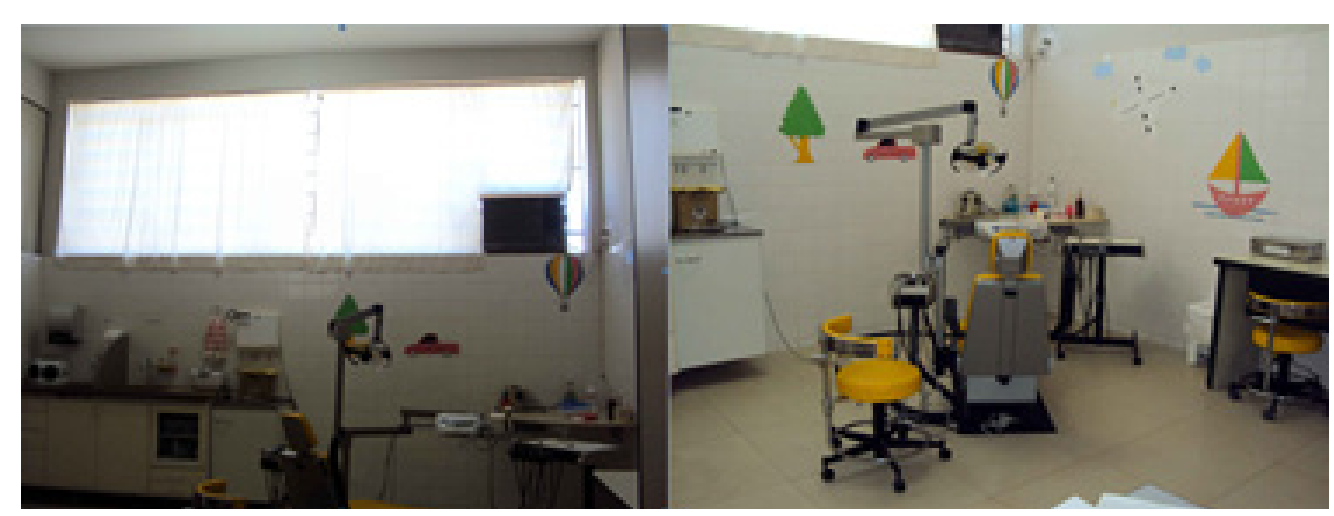

Figura 6 - vistas internas do consultório.

Fonte: Arquivo dos Autores.

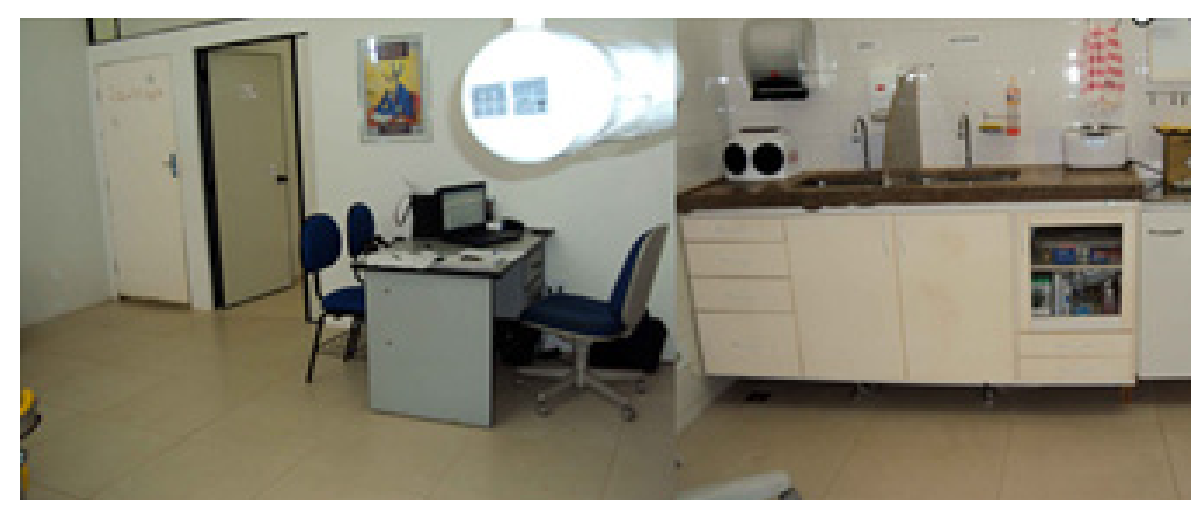

Figura 7 - vistas internas do consultório.

Fonte: Arquivo dos Autores.

As análises dos resultados obtidos com a aplicação das metodologias previamente definidas caracterizaram as seguintes situações:

- Questionário Nórdico de Sistemas Osteomusculares, quadro 04:

- Configurou em $100 \%$ como não havendo ocorrência de dores em nenhuma parte do corpo do profissional, nos últimos 7 e 12 dias; 
Consultório Odontológico: uma AET utilizando-se da EWA

- Configurou em $100 \%$ como não havendo a necessidade do profissional em deixar de trabalhar algum dia nos últimos 12 meses, devido à ocorrência de problemas com alguma parte do corpo.

\begin{tabular}{|l|l|l|l|}
\hline $\begin{array}{l}\text { Partes do corpo com } \\
\text { problemas }\end{array}$ & $\begin{array}{l}\text { Problemas nos } \\
\text { últimos 7 dias }\end{array}$ & $\begin{array}{l}\text { Problemas nos } \\
\text { últimos 12 dias }\end{array}$ & $\begin{array}{l}\text { Devido à problemas teve que } \\
\text { deixar de trabalhar algum dia } \\
\text { nos últimos 12 meses }\end{array}$ \\
\hline 1 - Pescoço & Não & Não & Não \\
\hline 2 - Ombros & Não & Não & Não \\
\hline $3-$ Cotovelos & Não & Não & Não \\
\hline $4-$ Punhos e mãos & Não & Não & Não \\
\hline $5-$ Coluna dorsal & Não & Não & Não \\
\hline 6 - Coluna lombar & Não & Não & Não \\
\hline $7-$ Quadril ou coxas & Não & Não & Não \\
\hline $8-$ Joelhos & Não & Não & Não \\
\hline $9-$ Tornozelos ou pés & Não & Não & Não \\
\hline
\end{tabular}

Quadro 4 - Resultados obtidos com a aplicação do Questionário Nórdico dos sintomas Osteomusculares. Fonte: Rasia (2004).

- EWA - Ergonomic Workplace Analysis

- A análise técnica, desenvolvida sob o ponto de vista subjetivo do avaliador, Gráfico 01, classificou o ambiente como possuindo condições predominantemente regulares, em $35,75 \%$.

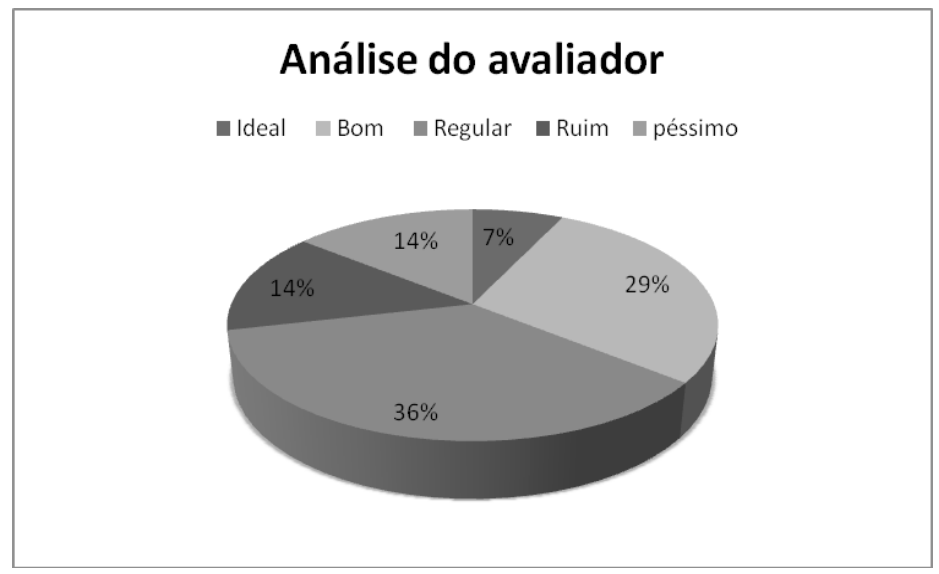

Gráfico 1 - Análise do avaliador

Fonte: Arquivo dos Autores.

Os itens que mostraram maiores problemas foram:

- Grande exigência de atenção: visto que os ciclos de trabalhos duram, em média, 30 a 50 minutos;

- Ruídos ambientais: a Norma Brasileira NBR 10152, definem que em ambientes de consultório odontológico o ruído não deve ultrapassar $68 \mathrm{~dB}(\mathrm{~A})$, este valor é corroborado pela Norma Regulamentadora do Ministério do Trabalho - NR 9. Os valores encontrados no consultório foram em média $66 \mathrm{~dB}$ e de $80 \mathrm{~dB}$ 
Mariana F. Bormio; Eliel S. Orenha; José C. P. da Silva; Ana Paula S. da Costa; João E. G.dos Santos

com a caneta de alta rotação ligada

- Espaço de trabalho:

- Área de trabalho horizontal

- Altura de trabalho

- Visão

- Espaço para as pernas

- Assento

- Ferramentas manuais

- Posturas de trabalho e movimentos:

- Pescoço-ombros

- Cotovelo - pulso

- Costas

- Quadril - pernas.

Pelo enfoque subjetivo e prático de uso do trabalhador, o ambiente foi classificado como possuindo condições regulares - 43\%, Gráfico 02. Os maiores problemas apontados relacionam-se às posturas de trabalho e movimentos assumidos: pescoço-ombros, cotovelo - pulso, costas, e quadril - pernas; além da preocupação com os riscos de acidentes, que foram considerados muito grandes e muito sérios, incluindo entre eles os físicos, ergonômicos, químicos e biológicos.

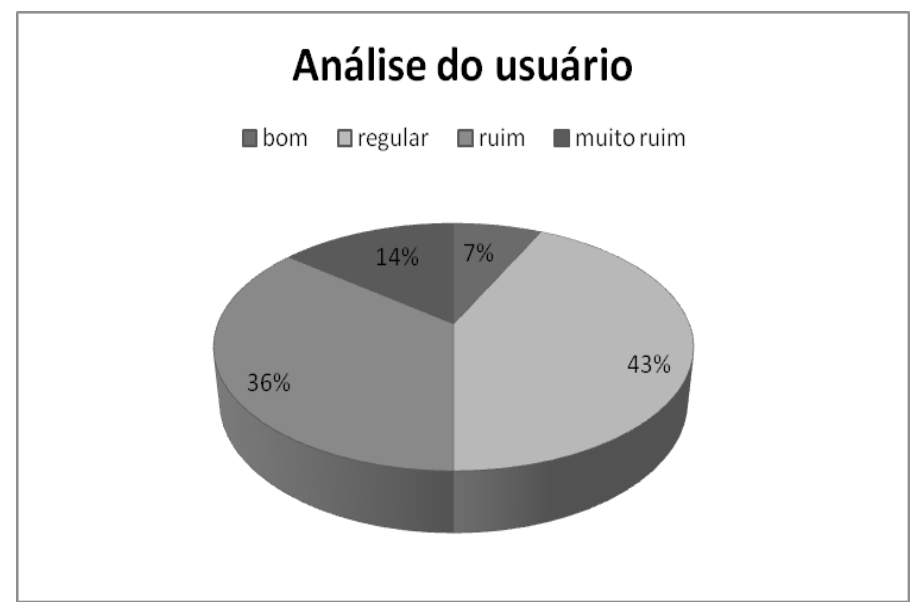

Gráfico 2 - Análise do usuário.

Fonte: Arquivo dos autores.

- Esquema Gráfico do ISO e FDI

- Aplicando esse Sistema Gráfico, figura 08, observou-se que o posto de trabalho ultrapassa os limites demarcados como sendo ideais para o alcance do profissional, pois, o layout da clinica não apresenta concentrado como deveria para que assim facilitasse o desenvolvimento das atividades do profissional. Conclui-se assim que precisa ser feita uma remodelação na distribuição dos equipamentos dentro do local. 


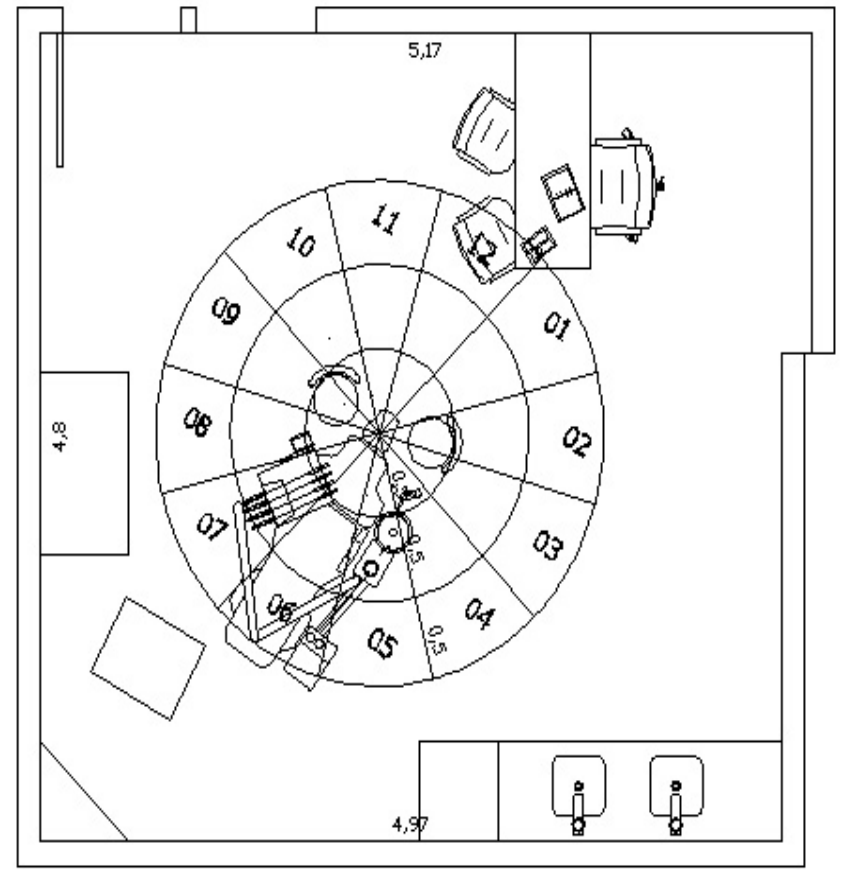

Figura 8 - Aplicação do esquema gráfico.

Fonte: Arquivo dos autores.

\section{Conclusões}

Finalizando esse trabalho pode-se dizer que os resultados obtidos, enquanto processo de aplicação das metodologias, foi satisfatório e tido como viável para utilização na segunda etapa do projeto, podendo ser aplicado de maneira eficaz.

No que diz respeito aos resultados dos protocolos, pode-se dizer que não foram identificados problemas com o sistema osteomuscular do trabalhador e que, os problemas identificados com o ambiente físico podem ser facilmente corrigidos.

Espera-se que através desse trabalho tenha-se instituído as primeiras contribuições para essa linha de pesquisa.

\section{Agradecimentos}

Agradece-se à contribuição valiosa do "Lar Escola Rafael Maurício, que permitiu a realização deste trabalho; e dos alunos do curso de Arquitetura e Urbanismo da Universidade Paulista, Campus de Bauru - SP; Amanda da Silva Camargo, Marlon Henrique Miranda da Rocha e Fábio Leandro Clarindo que atuam de maneira ativa no desenvolvimento do projeto.

\section{Referências}

AHONEM, M.; ILMARINEN, R.; KUORINKA, I.; LAUNIS, M.; LEHTELÄ, T.; LUOPAJÄRVI, T.; SAARI, J.; SEPPÄLÄ, P.; STÄLHAMMAR, H. Ergonomic workplace analysis. Helsinki: Finnish Institute of Occupational Health, 1989. 
Mariana F. Bormio; Eliel S. Orenha; José C. P. da Silva; Ana Paula S. da Costa; João E. G.dos Santos ASSOCIAÇÃO BRASILEIRA DE NORMAS TECNICAS. NBR 10152 (NB 95). Níveis de ruído para conforto acústico. Rio de Janeiro: ABNT, mar. 1987.

BORMIO, M. F. Avaliação pós-ocupação ambiental de escolas da cidade de Bauru (SP) e Lençóis Paulista (SP): um estudo ergonômico visto pela metodologia EWA. 2007. Dissertação (Mestrado em Desenho Industrial) - Faculdade de Arquitetura, Artes e Comunicação, Bauru.

BRASIL. Ministério da Saúde. Agência Nacional de Vigilância Sanitária. Serviços Odontológicos: prevenção e controle de riscos. Brasília: Ministério da Saúde, 2006.

CUSTODIO, Renata Aparecida Ribeiro. Análise ergonômica do trabalho aplicada à Odontologia : clínica geral - um estudo de caso. Dissertação (Mestrado) - Universidade Federal de Itajubá. Itajubá, 2006.

IIDA, I. Ergonomia: projeto e produção. 2. ed. São Paulo: Edgard Blücher, 2006.

ORNSTEIN, S.; ROMERO, M. Avaliação pós-ocupação (APO) do ambiente construído. São Paulo: Studio Nobel, 1992.

PINHEIRO, F. A.; TRÓCCOLI, B. T.; CARVALHO, C. V. de. Validação do questionário nórdico de sintomas osteomusculares como medida de morbidade. Revista de Saúde Pública, São Paulo, v. 36, n. 3, p. 307-312, 2002.

RASIA, D. Quando a dor é do dentista! custo humano do trabalho de endodontistas e indicadores de Dort. 2004. Dissertação (Mestrado em Psicologia Área de Concentração: Psicologia Social e do Trabalho) - Universidade de Brasília, Brasília. Disponível em: <http://vsites.unb.br/ip/ labergo/sitenovo/dissertacoes/OrientMC/Denise/Versao_Final.pdf>. Acesso em: 5 maio 2011.

SANTOS, V. M. V.; BASILIO, F. H. de M.; BARRETO, R. R.; OLIVEIRA, E. de S. Análise ergonômica das condições de trabalho dos dentistas: uma comparação entre a rede pública e o setor privado. In: ENCONTRO NACIONAL DE ENGENHARIA DE PRODUÇÃO, 27., 2007, Foz do Iguaçu. Anais... Foz do Iguaçu: ENEGEP, 2007. Disponível em: <http://www.abepro.org.br/biblioteca/ ENEGEP2007_TR600453_9748.pdf>. Acesso em: 5 maio 2011. 